\title{
FATIGUE LIFE OF DEPOSITED REPAIR WELDS ON SINGLE-CRYSTAL HIGH-TEMPERATURE NICKEL ALLOY UNDER CYCLIC OXIDATION
}

\author{
A.F. BELYAVIN, V.V. KURENKOVA and D.A. FEDOTOV \\ $\mathrm{RC} \ll$ Pratt\&Whitney-Paton» \\ 68 Gorky Str., Kiev, Ukraine. E-mail: vkurenkova@pwpaton.com
}

\begin{abstract}
In modern gas-turbine units increase of gas working temperature leads to shortening of blade service life. For this reason their repair becomes a priority. Retailoring of single-crystal blade tip by hardfacing is a rather complicated task. In order to select suitable filler material, thermal cycling tests of samples of deposited welds on CMSX-4 alloy with a single-crystal structure have been performed. Evolution of the structure under the conditions of high-temperature cyclic oxidation is considered. Selection of filler material, which ensures high temperature resistance and stability of weld metal structure, was optimized. These requirements are satisfied by $\mathrm{Co}-\mathrm{Ni}$-based material, which was earlier tried out and proved to be very good in complex technology of repair of a blade from ZMI-3U alloy. The technology includes airfoil tip retailoring by hardfacing with subsequent deposition on the item surface of a high-temperature metal coating by electron beam deposition to ensure the required service properties of the item. 18 Ref., 4 Tables, 10 Figures.
\end{abstract}

Key words: single-crystal alloy, hardfacing, dendritic growth, stray grains, raft structure, heat-affected zone, cyclic oxidation, oxidation resistance, coating, spinel, yttrium oxide

In connection with a significant increase of gas working temperature (by approximately $150{ }^{\circ} \mathrm{C}$ ) and rising level of thermal stress in blades of commercial gas-turbine unit (GTU) a need arose of development of new approaches to repair and deposition of coatings, which would ensure turbine blade protection from high-temperature gas corrosion and would increase resistance to thermal fatigue cracking, thus extending blade working life.

Gas temperature at the outlet of combustion chamber of a modern commercial GTU is equal to approximately $1420{ }^{\circ} \mathrm{C}$, accordingly, turbine inlet temperature is $1180-1200{ }^{\circ} \mathrm{C}$ for $45-47 \mathrm{MW}$ GTU.

Blade tip belongs to low-duty areas, where temperature is higher than $1000{ }^{\circ} \mathrm{C}$ and can reach $1050-1150{ }^{\circ} \mathrm{C}$ [1]. Service of gas turbines operating at a high temperature is characterized by non-uniform heating of blade airfoil surface in gas flow. In connection with non-symmetrical operation of combustion chambers gas flow temperature is non-uniform, leading to blades exposure to different temperatures at their rotation in the turbine and coming under the flame plume. Non-uniform heating leads to increase of internal thermal stresses: compressive stresses at temperature rise and tensile stresses at its lowering, causing thermal fatigue crack initiation in the depos-

(C) A.F. BELYAVIN, V.V. KURENKOVA and D.A. FEDOTOV, 2014 ited weld metal. Thus, thermal fatigue cracks parallel to blade axis can form at blade tip, in addition to corrosion and erosion damage (as a result of contact with labyrinth seal).

The main purpose of these studies consisted in selection of filler material having sufficient oxidation and corrosion resistance at working temperatures for repair (retailoring) of airfoil tip of a single-crystal blade (made from CMSX-4 alloy), that enables formation of defect free deposited welds. Deposited material should also match the material of the base and high-temperature electron beam coating deposited at the end of complex blade repair.

Materials and methods of investigation. The base for the blades was carbon-free second generation single-crystal alloy CMSX-4 (analog of JS32 alloy) of the following composition, wt. $\%$ : $\mathrm{Ni}-9 \mathrm{Co}-6.5 \mathrm{Cr}-$ $6 \mathrm{~W}-0.6 \mathrm{Mo}-6.5 \mathrm{Ta}-5.6 \mathrm{Al}-1 \mathrm{Ti}-3 \mathrm{Re}-0.1 \mathrm{Hf}$, which is characterized by high strength, structural stability and high creep resistance [2].

Samples (4 pcs), cut out of the blade root of GTE first stage were used in experiments. The surface for hardfacing of each sample was treated by endless abrasive belt KK711 R40 in PWS $3 / 200 \mathrm{DH}$ grinder.

Pulsed argon-arc surfacing was performed using HOBART 120 power source and three types of filler wire of 0.8 to $1.2 \mathrm{~mm}$ diameter. The process was conducted by moving the electrode in the direction normal to the prevailing direction of single-crystal growth $<001>$. At hardfacing the samples were clamped in the vise to ensure the hardfacing plane (110). Usually five beads 
Table 1. Composition of base and filler materials, wt.\%

\begin{tabular}{|c|c|c|c|c|c|c|c|c|c|c|c|c|c|c|c|}
\hline $\begin{array}{c}\text { Base alloy } \\
\text { and filler } \\
\text { wire variants }\end{array}$ & $\mathrm{Ni}$ & $\mathrm{Co}$ & $\mathrm{Cr}$ & $\mathrm{Al}$ & $\mathrm{Ti}$ & $\mathrm{W}$ & Mo & $\mathrm{Ta}$ & $\operatorname{Re}$ & $\mathrm{Nb}$ & Hf & $\mathrm{Si}$ & $\mathrm{Fe}$ & $\mathrm{C}$ & $\underset{\mathrm{Ti}}{\sum \mathrm{Al}+}$ \\
\hline CMSX-4 & Base & 9.0 & 6.5 & 5.6 & 1.0 & 6.0 & 0.6 & 6.5 & 3.0 & - & 0.1 & - & - & - & 6.6 \\
\hline PWA 795 & 15.0 & Base & 20.0 & 4.4 & 0.2 & 9.0 & - & 3.0 & - & - & 1.1 & $\begin{array}{c}0.045^{-} \\
0.1 Y^{-}\end{array}$ & - & 0.35 & 4.6 \\
\hline FSX 414 & 10.0 & Same & 29.0 & - & - & 7.5 & - & - & - & $0.5 \mathrm{Mn}$ & - & - & $<1.0$ & 0.25 & - \\
\hline IN 625 & Base & 1.0 & 21.5 & 0.4 & 0.4 & - & 9.0 & - & - & 3.65 & - & 0.5 & $0.5 \mathrm{Mn}$ & 0.1 & $<0.8$ \\
\hline
\end{tabular}

were deposited on samples. After deposition of each bead, the surface was scraped by a metal brush. After hardfacing the samples were annealed in vacuum at $950{ }^{\circ} \mathrm{C}(2 \mathrm{~h})$ to relieve welding stresses.

Evaluation of deposited weld quality was performed visually with application of liquid-penetrant inspection, and on microsections using scanning electron microscope CamScan-4, fitted with energy-dispersive analyzer ENERGY 200 (with INCA software). Deposited weld microhardness was measured in Micro-Duromat 4000E instrument at 10-20 g load.

To perform comparative assessment of oxidation resistance of the studied filler materials CMSX-4 alloy samples with deposited beads were tested for cyclic oxidation in CM FURNACES Bloomfield-1710BL (c) unit in the following mode: heating up to $1150{ }^{\circ} \mathrm{C}$ for $5 \mathrm{~min}+$ soaking at maximum temperature for $50 \mathrm{~min}+$ cooling to $50{ }^{\circ} \mathrm{C}$ for $5 \mathrm{~min}$ [3]. This mode is used for assessment of thermal-fatigue life of coated samples. Testing conditions were quite hard and only slightly different from temperature conditions of operation of blades in real engines. Upper test temperature was close to the real temperature $\left(1050-1150{ }^{\circ} \mathrm{C}\right)$ on blade airfoil surface in modern GTU.

Oxidation resistance was assessed by the weight method by relative change (reduction) of sample weight by plotting kinetic oxidation curves, as well as by the depth of frontal and local oxidation during the time of testing (400 thermal cycles) of deposited welds obtained using various filler materials. It is recommended to apply the method of direct measurements of corrosion depth at non-uniform oxidation process. Sample of CMSX-4 base alloy was also subjected to thermal cycling tests as a reference.

Oxidation resistance of deposited welds was first of all determined visually - by examination of samples after each 50 thermal cycles to detect intensive oxidation areas, and relative change of deposited weld mass was determined by comparison to initial condition (in view of complex con- figuration of samples) - by the gravimetric method.

In order to ensure oxidation and corrosion resistance of deposited material, preference was given to high-chromium (with about 20 wt.\% Cr) filler materials based on nickel or cobalt. Four variants of alloys for hardfacing were considered: IN 625/FSX 414; PWA 795; IN 625; FSX 414 (Table 1).

Deposited weld structure was studied on microsections in as-deposited condition and after completion of thermal cycling tests.

Experimental. The criteria for assessment of weld quality were absence of cracks or other defects, initiating at weld formation under the conditions of following the orientation of the substrate and direction of welding source motion (normal to prevailing direction of single-crystal growth).

As was noted in [4], surfacing of single crystal blades has several significant special features. Basic criteria for deposited weld quality and structural perfection of growth single-crystal structure are orientation uniformity of the weld and line of fusion with the base metal; absence of stray grains (SG) in the weld [5]; and absence of solidification cracks or other defects.

It is established that by controlling the weld pool shape at argon TIG process, it is possible to ensure a flat solidification front, on which conditions are created for directional solidification, allowing preservation of prevailing growth direction of the single crystal up to $1 / 2-2 / 3$ of full weld height minimum. Minimum speed of pulsed argon-arc surfacing and power input of the process prevent formation of SG, and, consequently, of intergranular cracks on the solidification front.

As is seen from cross-sectional structures of welds, deposited with application of various materials, before and after thermal cycling tests (Figure 1), the formed deposited welds had quite dense defect-free structures, which differed as a result of application of alloys of various alloying 


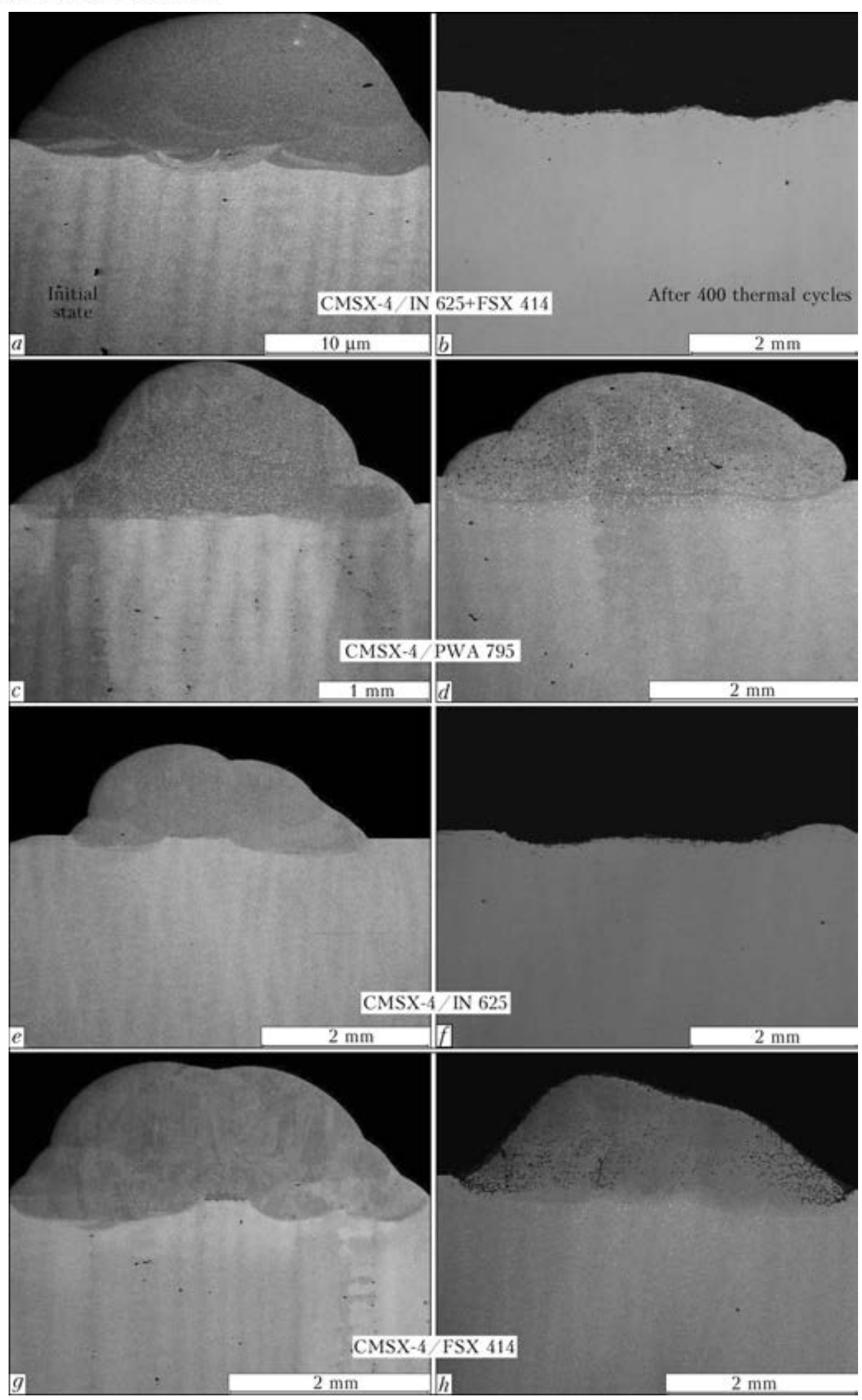

Figure 1. Structure of deposited welds on CMSX-4 samples with application of different fillers before $(a, c, e, f)$ and after $(b, d, f, h)$ thermal cycling tests

systems, namely oxidation-resistant nickel alloy IN 625 and cobalt corrosion-resistant alloys PWA 795 and FSX 414. In weld fusion zone, equal to 30-100 $\mu \mathrm{m}$, structural perfection of growth single-crystal structure and epitaxial growth of the single crystal in the deposited weld were visible (Figure 2).

At investigation of various weld sections, including root sections (with overheating at the start of the process), a significant influence of 


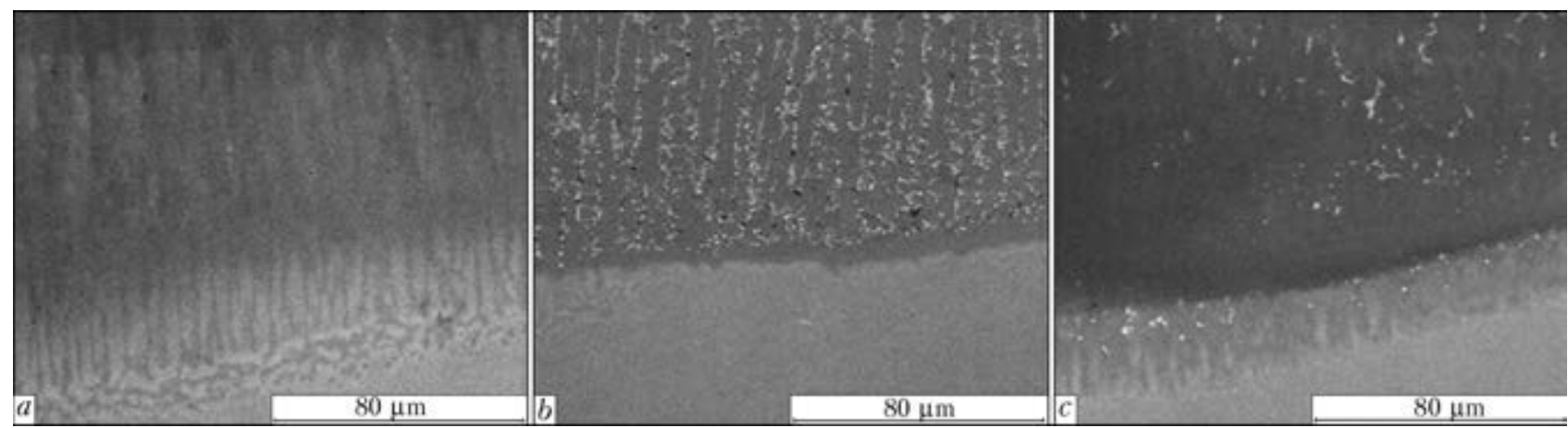

Figure 2. Microstructure of fusion line of welds made on CMSX-4 alloy samples using fillers IN 625 ( $a$ ), PWA 795 (b) and FSX 414 (c)

filler material on deposit integrity and quality was found, namely: stray grains appeared, as a rule, at formation of a curvilinear solidification front. At application of nickel alloys as filler materials, solidification cracks formed along the boundaries of such grains during solidification or postweld heat treatment both on fusion line and in the weld proper (Figure 3, $a, c$ ). This was not observed in case of application of cobalt filler materials (Figure $3, b, d$ ). Even in the presence of defects in the base (subgrains with high-angle boundaries, pores, etc., see Figure $3, b, d$ ) formation of coarse SG on the fusion line did not lead to initiation and propagation of intercrystalline cracks. This is attributable to the fact that in cobalt alloys there is no phenomenon of solidphase dispersion strengthening (characteristic for high nickel alloys), i.e. precipitation of particles of strengthening $\gamma^{\prime}$-phase from the solid solution induces dispersion hardening cracks in deposited welds.

For clear understanding of the process of deposited layer oxidation and degradation on the single crystal we, first of all, considered the evolution of base microstructure as a result of longterm high-temperature impact. Structure of initial single-crystal alloy CMSX-4 is $\gamma$-solid solution, strengthened by $\gamma^{\prime}$-phase particles of $0.2-$ $0.5 \mu \mathrm{m}$ size, the volume fraction of which is equal to approximately $71.5 \%[6]$ (Figure $4, a, c, e$ ). After long-term high-temperature cyclic testing, as a result of diffusion processes in single-crystal alloy, particles of strengthening $\gamma^{\prime}-\mathrm{Ni}_{3} \mathrm{Al}$ phase coagulate with a change in morphology, and in-

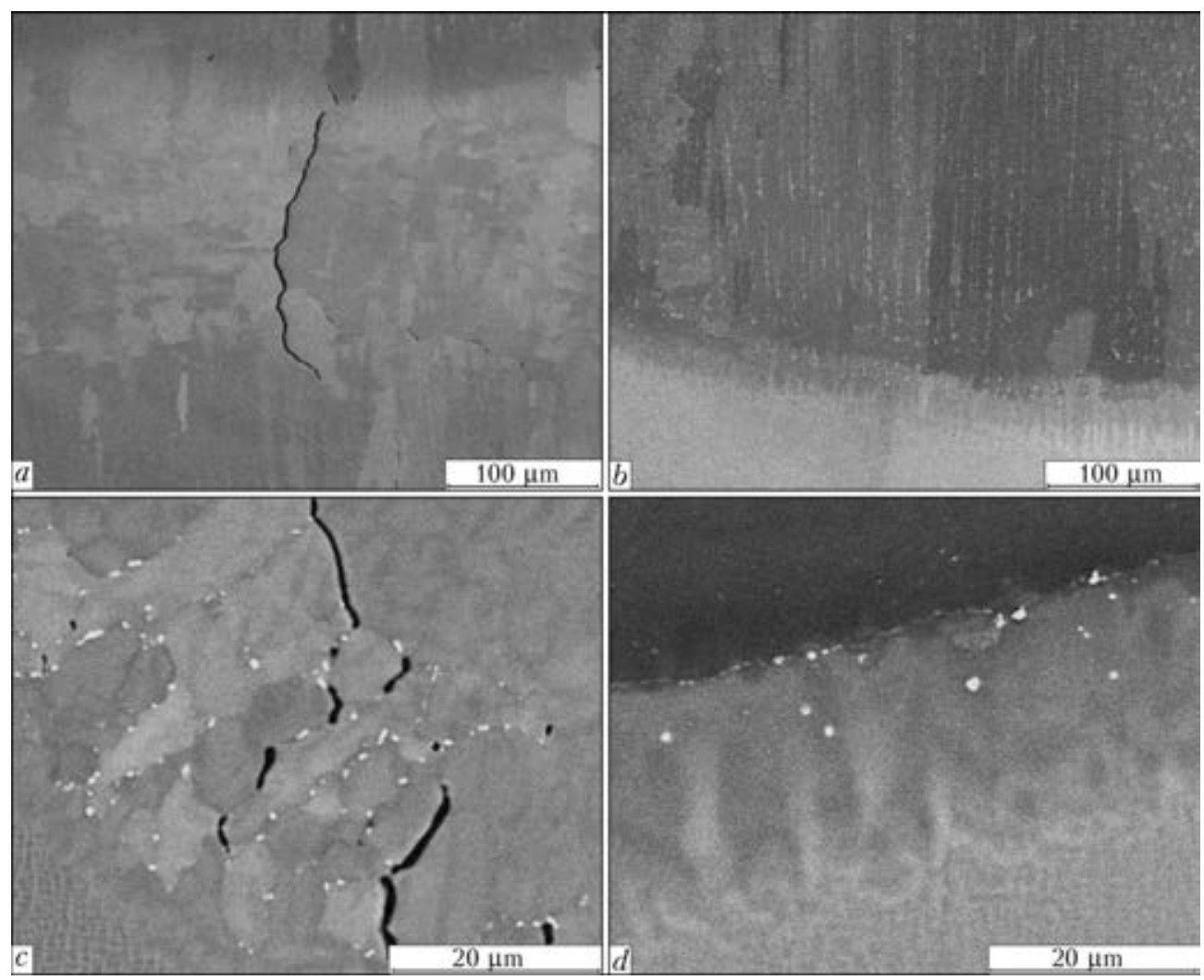

Figure 3. Defects in the structure of welds deposited with application of filler materials on nickel $(a, c)$ and cobalt $(b$, d) base 

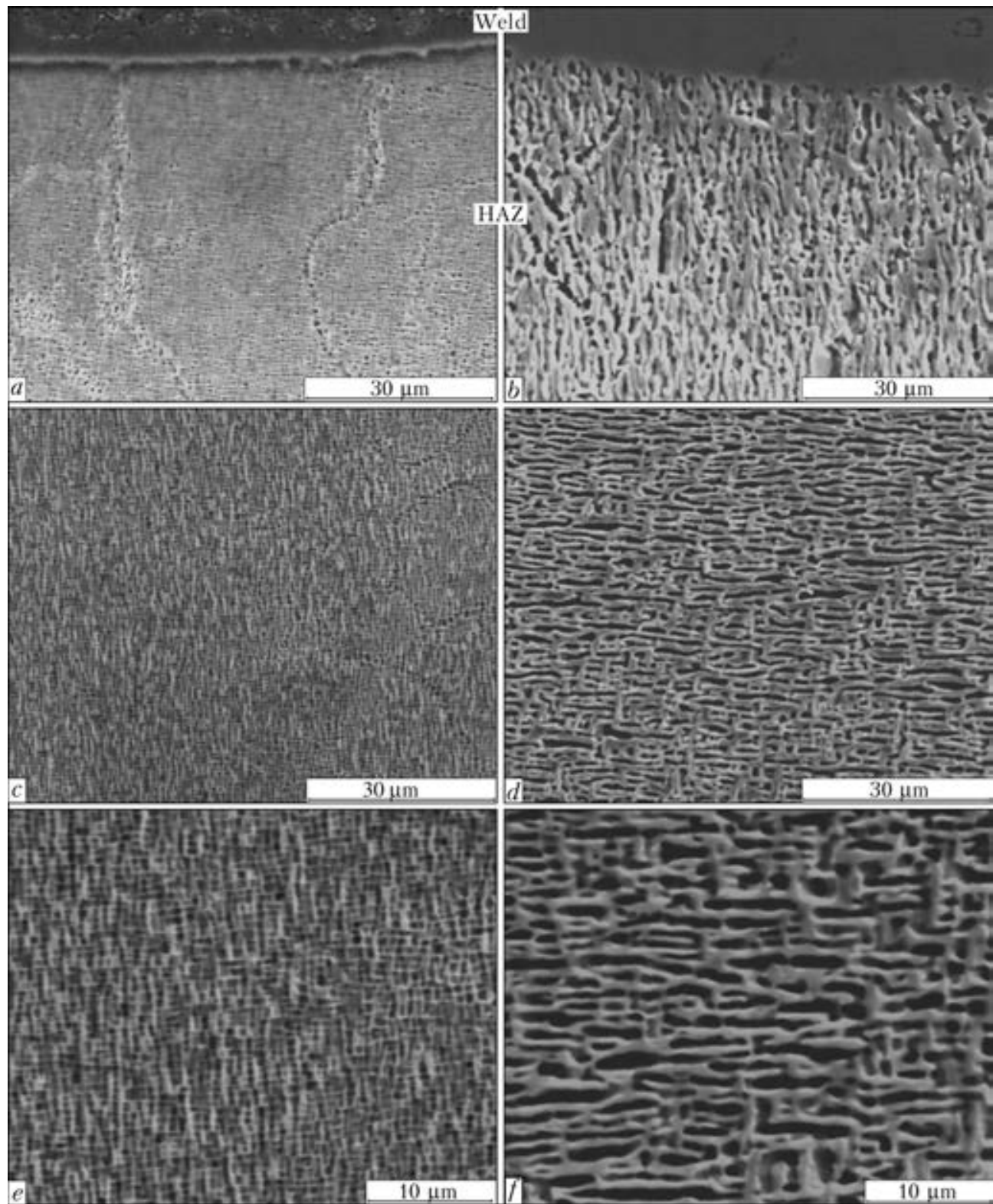

Figure 4. Evolution of $\left(\gamma-\gamma^{\prime}\right)$-microstructure of CMSX-4 alloy before $(a, c, e)$ and after $(b, d, f)$ thermal cycling tests

tergrow, forming so-called raft structure of parallel plates up to $10 \mu \mathrm{m}$ long (Figure $4, b, d, f$ ). The negative misfit (discrepancy between crystalline lattice periods of the main structural $\gamma$ and $\gamma^{\prime}$-phases) is one of the causes for internal stress initiation [7]. Under the impact of these stresses and temperature gradient (changes of thermal stress sign at heating-cooling) in the case of thermal cyclic testing cuboidal particles of $\gamma^{\prime}$-phase coalesce in a specific way by intergrowing into plates or rods, which are oriented along $<101>$ direction with equal probability (Figure 4, $d, f$ ) $[6,8]$.

Raft structure under the conditions of external load application thermodynamically is a more equilibrium system, as the level of interphase surface energy in it is lower than in the structure with cubic dispersed precipitates of $\gamma^{\prime}$-phase. In single crystals in the absence of carbide phases and with minimum amount of eutectic $\gamma^{\prime}$-phase, raft structure is more perfect and less prone to local changes. In addition, it ensures a lower rate of material softening, namely improves creep resistance, and preventing dislocation motion through the layer $[8,9]$.

As shown in [10], material deformation at thermal impact under thermal cycling conditions develops by the mechanism of active tensioncompression. At long repetition of compressiontension cycle this causes formation of a substructure, fabourable for crack initiation, particularly at the stage of cooling and increase of tensile stresses. An important feature of single crystal deformation is preservation of initial crystallographic orientation of blade axis at multiple cyclic heating and cooling. 
During pulsed hardfacing of single-crystal alloy a HAZ is formed. In this region (30 to $50 \mu \mathrm{m}$ depth) temperature impact results in partial dissolution of strengthening $\gamma^{\prime}$-phase (see Figure 4, $a$ ). During thermal impact at cyclic oxidation not only repeated precipitation of $\mathrm{Ni}_{3} \mathrm{Al}$ intermetallic phase, but also its evolution towards enlargement and coarsening occur in the considered volume. However, after 400 thermal cycles no intergrowing of strengthening phase plates or formation of raft structure were observed in the HAZ $\left(\gamma+\gamma^{\prime}\right)$ microstructure, that was clearly seen in all other regions of base material ( $\mathrm{Fi}^{-}$ gure $4, b, d, f)$.

Dependence of sample weight change under the conditions of thermal cycling tests $(50 \leftrightarrow$ $\leftrightarrow 1150{ }^{\circ} \mathrm{C}$ ) is given in Figure 5. CMSX-4 base alloy is a high-temperature thermally stable material. Its oxidation intensity at thermal cycling is low (compared to some of the considered filler materials), that points to a relatively small angle of inclination of exponential oxidation curve.

After 400 thermal cycles the depth and nature of oxidation product distribution both in base material (CMSX-4 alloy) and in weld material was determined (Figure 6). After oxidation at $t_{\max }=1150{ }^{\circ} \mathrm{C}$ of $\mathrm{CMSX}-4$ alloy its scale consists of two layers: outer layer of $4 \mu \mathrm{m}$ thickness of complex spinel based on nickel $\mathrm{Ni}, \mathrm{Co}(\mathrm{Cr}, \mathrm{Al})_{2} \mathrm{O}_{4}$, and inner layer of $5 \mu \mathrm{m}$ thickness based on $\mathrm{Al}_{2} \mathrm{O}_{3}$ oxide. Aluminium oxide based film is predominantly continuous and determines the alloy oxidation resistance (Figure $7, a$ ). On the other hand, at rapid cooling of the alloy under cyclic oxidation conditions $\mathrm{Al}_{2} \mathrm{O}_{3}$ protective film cracks and delaminates. At each repeated cycle the film $\left(\mathrm{Al}_{2} \mathrm{O}_{3}\right.$ oxide $)$ forms again, but with smaller aluminium content in it. The latter is consumed from subsurface layers of base alloy, leading to depletion of its stock and lowering of base oxidation temperature resistance [11]. At protective film spallation formation of nickel oxide film and spinel-based suboxide film at the depth of the order of $120 \mu \mathrm{m}$ at frontal oxidation to the depth of $8^{-10 \mu \mathrm{m}}$ was observed on sample surface in some locations.

At longer testing time samples with deposited welds, made with application of IN 625 nickel filler, oxidized more intensively at high temperature than those made with cobalt filler. During the total time of thermal cycling tests (400 thermal cycles) deposited welds burnt out completely: material was oxidized, and oxidation products spalled off at cooling, that was observed both visually and on microsections (see Figure 1, $b, f$ and Figure $7, b)$. HAZ under the degraded

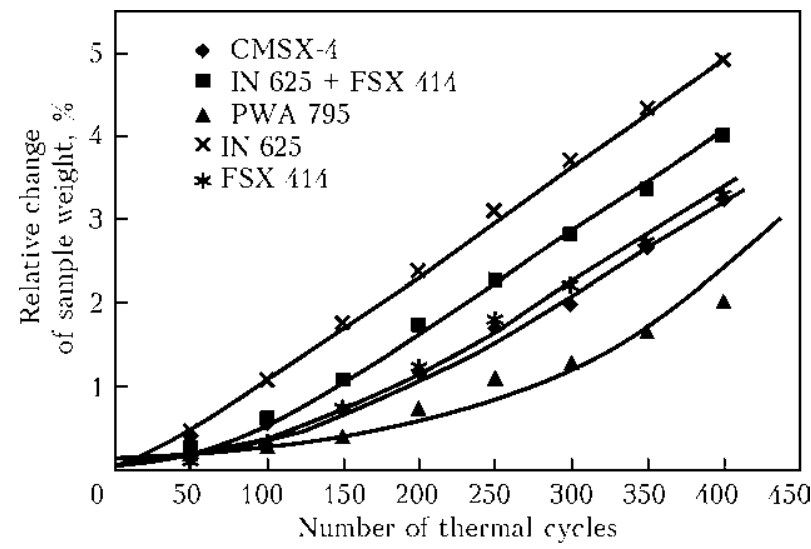

Figure 5. Kinetics of oxidation of various filler materials and CMSX-4 alloy

weld was also subjected to internal oxidation (Figure 7,b): areas of local and frontal damage of alloy surface and precipitation of a large number of discrete oxide and coarse nitride phases were observed, that is indicative of an essential degradation of base material under the weld.

Selection of IN 625 alloy as filler material for single crystal hardfacing was predetermined by its high fatigue resistance, rupture strength, satisfactory creep resistance, oxidation resistance, weldability and adaptability to fabrication. However, these properties of the alloy are preserved at limit service temperature of $900-950{ }^{\circ} \mathrm{C}$. Alloying of IN 625 alloy by titanium, molybdenum and niobium ensures its oxidation resistance. However, at more than 3 wt.\% Mo (IN 625 alloy contains 9 wt.\% Mo) its oxidation resistance drops, as at heating above $900{ }^{\circ} \mathrm{C}$ molybdenum oxide $\mathrm{MoO}_{2}$ is volatile.

Chromium included in IN 625 composition in the amount of $21.5 \mathrm{wt} \%$ provides reliable protection from oxidation and corrosion at temperature of 950 to $1000{ }^{\circ} \mathrm{C}$, forming $\mathrm{Cr}_{2} \mathrm{O}_{3}$ film. $\mathrm{Cr}_{2} \mathrm{O}_{3}$ protective properties decrease with temperature rise (above $1000{ }^{\circ} \mathrm{C}$ ) in air, as $\mathrm{Cr}_{2} \mathrm{O}_{3}$ transformation into volatile $\mathrm{CrO}_{3}$ oxide takes place. Ac-

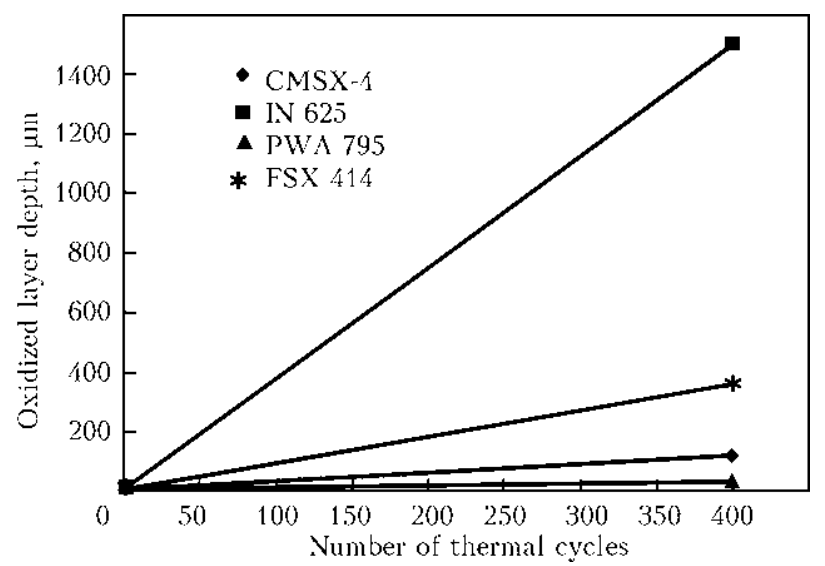

Figure 6. Dependence of thickness of scale film on deposited weld surface on various fillers after thermal cycling tests 


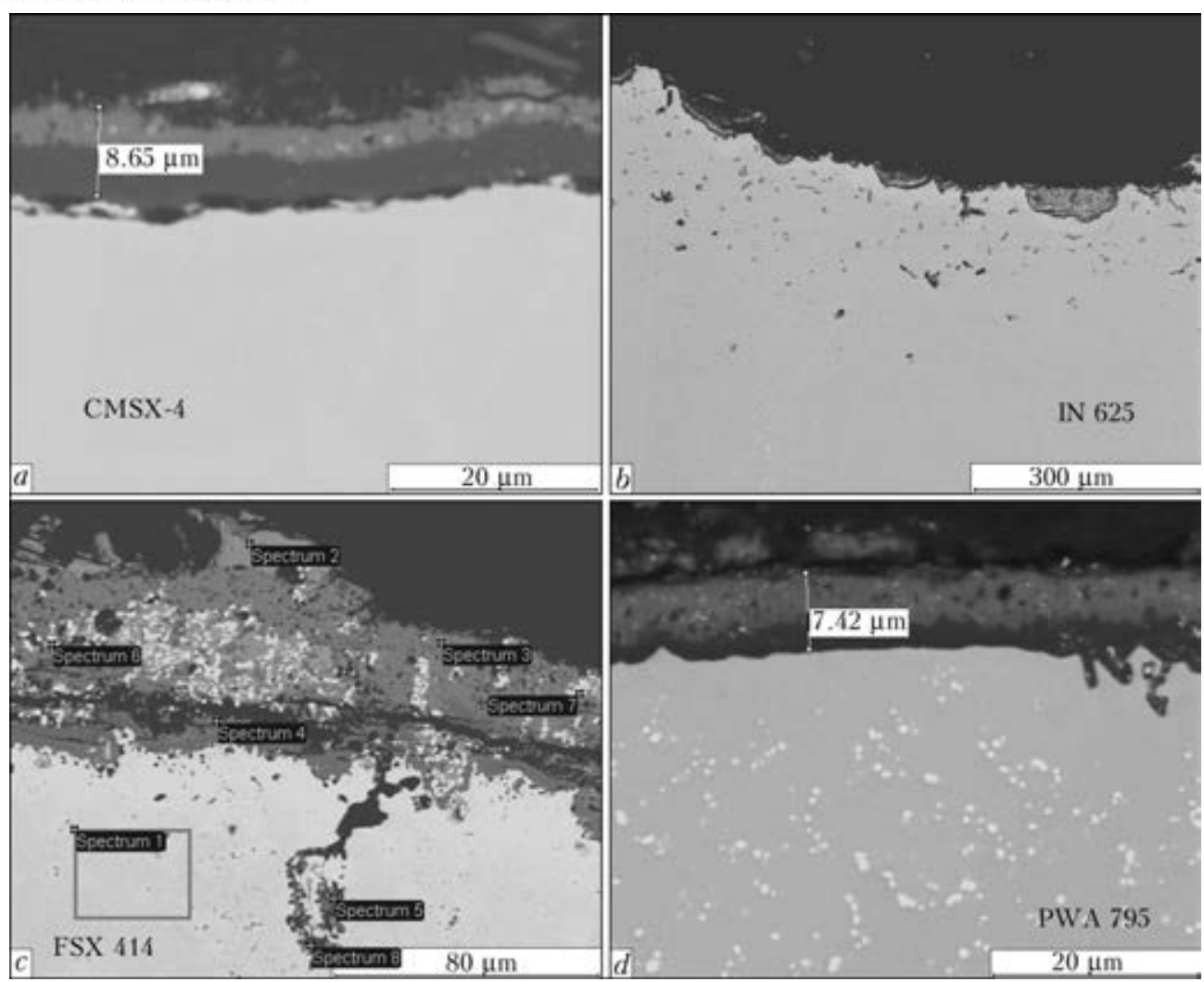

Figure 7. Oxide film on the surface of base metal $(a)$ and deposited welds $(b-d)$ formed using various filler materials after 400 thermal cycles

cordingly, at maximum testing temperature of $1150{ }^{\circ} \mathrm{C}$, surface layer of spinel and protective film, based on chromium oxide (III) adjacent to weld metal, break up. Reduction of sample weight at oxidation at temperature above $1100^{\circ} \mathrm{C}$ is also related to possible scale evaporation.

Welds formed by cobalt-based fillers have successfully resisted $400 \mathrm{~h}$ of cyclic testing at $1150{ }^{\circ} \mathrm{C}$. Kinetic curves of sample oxidation are located in the plot lower part (see Figure 5), that is indicative of a lower oxidation rate compared to nickel fillers.

Table 2. Composition of deposited weld formed with application of filler wire FSX 414 after 400 thermal cycles, wt.\% (see Figure $7, c)$

\begin{tabular}{||c|c|c|c|c|c|c||}
\hline \hline Spectrum & $\mathrm{C}^{*}$ & $\mathrm{O}$ & $\mathrm{Cr}$ & $\mathrm{Co}$ & $\mathrm{Ni}$ & $\mathrm{W}$ \\
\hline 1 & - & 0.26 & 20.84 & 56.96 & 14.16 & 7.77 \\
\hline 2 & - & 21.68 & 2.27 & 54.92 & 20.89 & 0.25 \\
\hline 3 & - & 31.58 & 35.96 & 26.84 & 2.87 & 2.75 \\
\hline 4 & - & 32.93 & 39.39 & 23.61 & 4.08 & - \\
\hline 5 & 12.39 & 37.91 & 45.79 & 2.67 & 2.86 & 0.38 \\
\hline 6 & 5.32 & 19.07 & 4.06 & 25.42 & 9.18 & 40.94 \\
\hline 7 & - & 28.78 & 27.21 & 26.65 & 3.10 & 14.26 \\
\hline 8 & 24.66 & 18.28 & 46.94 & 5.92 & 3.31 & 0.89 \\
\hline
\end{tabular}

*Here and in Table 4 carbon for determination of structural phase type is given qualitatively because of instrument malfunction (scale on the sample).
Application of FSX 414 alloy as filler material allowed forming a quite dense oxidation-resistant deposited weld on CMSX-4 alloy (see Figure 1, $h$ and Figure $7, c$ ). Main alloying component of FSX 414 cobalt alloy ( 29 wt.\% Cr) ensured reliable oxidation resistance of deposited material at increased temperature. Matrix solution of FSX 414 alloy is strengthened by addition of tungsten (7.5 wt.\%) and dispersion-strengthened by carbides predominantly of $\mathrm{Me}_{23} \mathrm{C}_{6}$ type (0.10.15 wt.\% C). Other types of carbides (based on tantalum and hafnium from base alloy) were also present in the bottom part of the already formed weld.

Thickness of frontal oxidation products on the surface of metal of weld from FSX 414 alloy after testing was 40 to $80 \mu \mathrm{m}$, and internal oxidation depth was $400 \mu \mathrm{m}$ (Figure 7,c). Heterogeneous morphology of oxide film on weld surface from cobalt-, chromium- and nickel-based spinels and localized penetration of oxidation products along grain boundaries to $50 \mu \mathrm{m}$ depth were observed (see Table 2). As follows from weld microstructure, after 400 thermal cycles of testing the most intensive oxidation occurred in the point of interaction of three components, namely base alloy, deposited material, and furnace atmosphere proper. In the lateral zones of weld adjacent to the base, i.e. in zones of the most active interdiffusion, local formation of oxidation products 


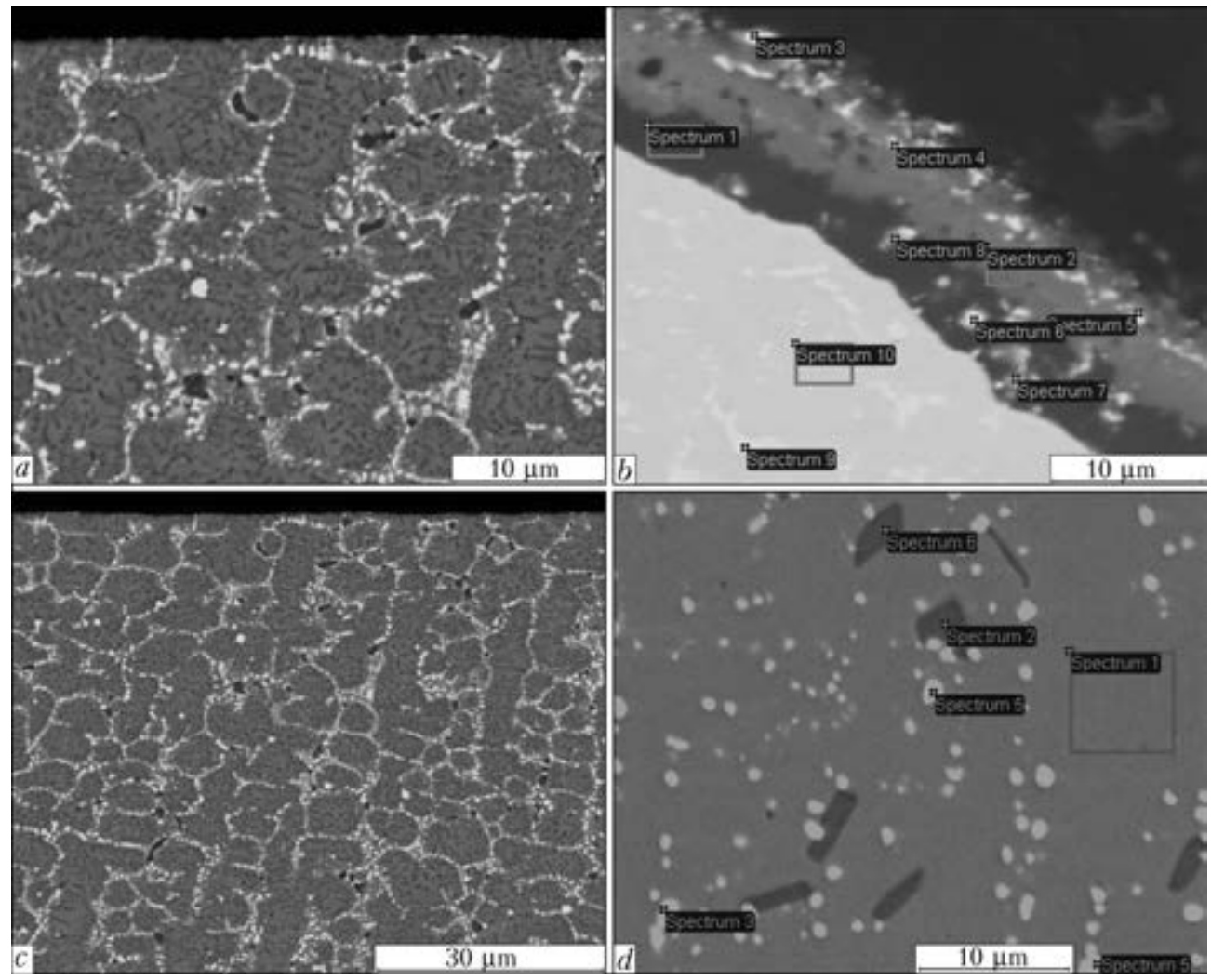

Figure 8. Evolution of the structure of filler material PWA 795 before $(a, c)$ and after $(b, d)$ thermal cycling tests

(oxides, nitrides) in the metal of weld and HAZ was observed (see Figure 1, $h$ ). Contrarily, weld center and the region of interphase boundary of deposited metal and base were not prone to oxidation and material degradation, respectively. Thus, at thermal cycling oxidation the deposit material - FSX 414 alloy - demonstrated satisfactory results on oxidation resistance, and the weld deposited with it on CMSX-4 single-crystal alloy was mostly preserved (even in the presence of polycrystalline structure on the fusion line, see Figure $3, b$ ).

As is seen from Figure 5, kinetic curve of oxidation of a sample with a deposit from PWA 795 alloy $\quad(\mathrm{Co}-15 \mathrm{Ni}-20 \mathrm{Cr}-4.4 \mathrm{Al}-8.7 \mathrm{~W}-2.7 \mathrm{Ta}-$ $1 \mathrm{Hf}-0.045 \mathrm{Y}-0.35 \mathrm{C}$ ) is the lowest. This material turned out to be the most oxidation-resistant by the results of high-temperature cyclic testing. Application of cobalt-based alloy ensured minimum oxidation rate of deposited weld (see Figure 1, $c)$, which preserved its configuration after 400 thermal cycles of testing (see Figure 1, $d, h$ ).

In the structure of initial weld, deposited with PWA 795 alloy, oriented columnar dendritic growth of solidified metal along single crystal direction [001] is clearly traced over the entire solidification front (see Figure 1, $c, d$ ). At preservation of a plane solidification front epitaxial growth of deposited metal was observed on the fusion line, when dendrites of excess solid solu- tion based on deposited metal solidify inheriting the lattice of base metal grains (see Figure 2, $b$ ). As regards the fine structure of weld metal, it has a three-phase structure. Its base is matrix $\gamma$-solid solution and carbide phase network, fringing fine dendrites (Figure $8, a, c$ ). As a rule, MeC type carbides based on hafnium, tantalum, zirconium, etc. form at solidification from liquid.

After thermal cyclic testing the depth of frontal oxidation over the entire surface of weld based on PWA 795 alloy was equal to $9-10 \mu \mathrm{m}$. Protective film was dense and had a two-layer structure, and good adhesion to deposited weld metal was noted (see Figure $7, d$ and Figure $8, b$ ). The inner layer adjacent to the base by its chemical composition corresponded to protective $\mathrm{Al}_{2} \mathrm{O}_{3}$ film, and outer layer - to spinel of $(\mathrm{Ni}, \mathrm{Co})$ $(\mathrm{Cr}, \mathrm{Al})_{2} \mathrm{O}_{4}$ type with $\mathrm{Al}_{2} \mathrm{O}_{3}, \mathrm{TaO}$ and $\mathrm{Y}_{2} \mathrm{O}_{3}$ inclusions (Table 3) [11, 12].

Microhardness of weld metal deposited with PWA 795 alloy (Figure 9) reflects the changes which occur on deposit/base interphase during cyclic oxidation. After surfacing microhardness of weld metal reached $4800 \mathrm{MPa}$, that is due to strengthening of matrix solution by interdendrite network of carbide phases. During testing diffusion processes run actively in the weld metal, causing partial dissolution of secondary strengthening phases, in particular, $\mathrm{MeC}$ carbides based on tantalum and hafnium which were trans- 
SCIENTIFIC AND TECHNICAL

Table 3. Composition of oxide film on the surface of welds deposited with application of filler wire PWA 795 after 400 thermal cycles, wt.\% (see Figure $8, b$ )

\begin{tabular}{|c|c|c|c|c|c|c|c|c|c|c|}
\hline Spectrum & $\mathrm{O}$ & $\mathrm{Al}$ & $\mathrm{Ti}$ & $\mathrm{Cr}$ & Co & $\mathrm{Ni}$ & $\mathrm{Y}$ & $\mathrm{Hf}$ & $\mathrm{Ta}$ & W \\
\hline 1 & 50.86 & 46.85 & - & 0.64 & 1.14 & 0.51 & - & - & - & - \\
\hline 2 & 40.90 & 25.05 & - & 6.03 & 18.05 & 9.97 & - & - & - & - \\
\hline 3 & 28.74 & 1.73 & 1.07 & 0.82 & 2.11 & 1.18 & 13.25 & 28.91 & 18.59 & 3.61 \\
\hline 4 & 35.93 & 10.94 & 0.59 & 3.76 & 10.34 & 5.59 & 5.73 & 3.86 & 15.30 & 7.96 \\
\hline 5 & 39.92 & 17.73 & 1.08 & 5.42 & 14.65 & 8.10 & - & 3.33 & 9.34 & 0.43 \\
\hline 6 & 36.56 & 20.56 & 2.33 & 0.96 & 1.25 & 0.46 & - & 6.55 & 29.53 & 1.82 \\
\hline 7 & 42.26 & 30.38 & 1.22 & 0.49 & 1.03 & 0.18 & - & 6.27 & 17.06 & 1.13 \\
\hline 8 & 45.11 & 24.28 & 2.09 & 1.68 & 2.13 & 1.18 & - & 5.54 & 16.59 & 1.40 \\
\hline 9 & - & 1.20 & 2.10 & 9.21 & 18.87 & 7.57 & - & 20.18 & 36.89 & 3.98 \\
\hline 10 & - & 3.81 & - & 21.07 & 45.19 & 18.67 & - & - & 0.71 & 10.55 \\
\hline
\end{tabular}

formed into globular discrete forms. Lowering of weld microhardness to $3200 \mathrm{MPa}$ is associated with it. Smoothing of the curve on the graph along the fusion line is indicative of the processes of diffusion and homogenizing of deposit material composition.

Increased oxidation resistance of the deposit from PWA 745 cobalt alloy is achieved due to optimum selection of deposited material composition, containing, in addition to basic elements, also other alloying elements, such as 2.7 wt.\% Ta, 1 wt.\% Hf and 0.045 wt.\% Y. Let us consider the influence of (contribution) of each of the cobalt alloy components to functional characteristics of the deposit of single-crystal nickel alloy CMSX-4.

Alloying system $(\mathrm{Co}-\mathrm{Ni}-\mathrm{Cr}-\mathrm{Al}-\mathrm{W})$ of filler PWA 795 alloy has high thermal structural stability (compared to other nickel fillers) in the temperature range of $800-1100{ }^{\circ} \mathrm{C}$, as here $\gamma \rightarrow$ $\rightarrow \gamma^{\prime}$ phase transformation at cooling in the range of $900-700{ }^{\circ} \mathrm{C}$ is eliminated. Such a phase transformation is associated with volume changes, particularly increase of temperature coefficient of linear expansion of material, leading to high ther-

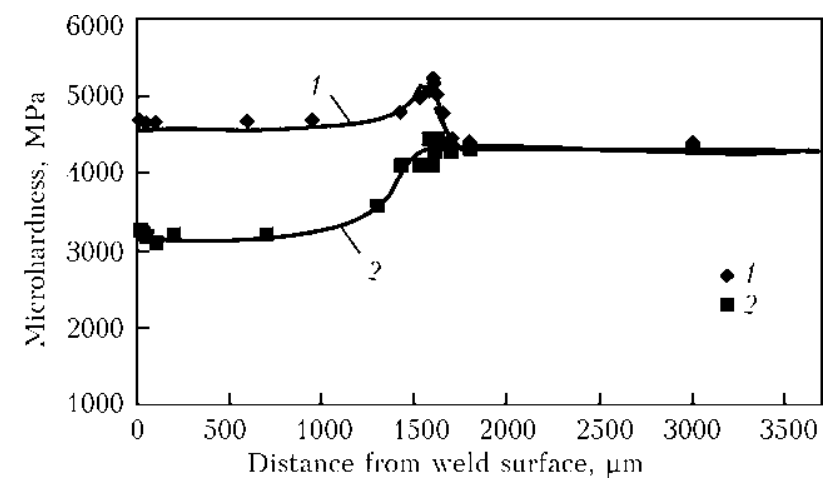

Figure 9. Microhardness of weld metal deposited by PWA 795 filler on single-crystal alloy CMSX-4 before (1) and after (2) thermal cycling tests mal stresses, which arise in the oxide film at cooling $[9,12]$. Cobalt, being the base of PWA 795 filler material, increases chromium solubility (its content is $20 \mathrm{wt. \%}$ ) in the matrix, hindering formation of brittle chromium phase $\alpha$-Cr, which forms in nickel systems jointly with $\gamma^{\prime}-\mathrm{Ni}_{3} \mathrm{Al}$ and lowers material creep resistance. On the whole, $\alpha$-Cr particles have a negative effect on mechanical properties, for instance, on fatigue resistance. On the other hand, chromium and aluminium improve oxidation resistance of the deposit.

Presence of about 15 wt.\% Ni stabilizes FCC lattice of cobalt-based solid solution, and chromium and tungsten (8.7 wt.\%) strengthen the solid solution, respectively.

Tantalum and hafnium in the amount of 2.7 and 1 wt.\% jointly present in material composition, improve mechanical properties of nickel-cobalt alloys, strengthening $\gamma$-solid solution (tantalum) and refining the carbide phase morphology.

Although low-carbon compositions of filler materials are mostly applied for single crystal surfacing, in the case of PWA 795 alloy carbon content reaches 0.35 wt.\%. However, presence of this component does not promote development of diffusion processes on the fusion line, in view of formation of carbide phases of $\mathrm{MeC}$ type, i.e complete binding of carbon into a chemical compound. At a rather wide range of mutual solubility and high formation temperature, $\mathrm{MeC}$ carbides have the shape close to a round one. Carbides, being located along dendrite/grain boundaries and inside dendrite cells, have the modifying functions, promote grain refinement and prevent recrystallization at high temperature. They strengthen both the grain proper, and its boundaries, slowing down diffusion processes and dislocation migration, and thus increasing the alloy thermal stability. From this viewpoint 
Table 4. Composition of weld metal deposited with application of PWA 795 filler wire after 400 thermal cycles, wt.\% (see Figure 8, $d$ )

\begin{tabular}{|c|c|c|c|c|c|c|c|c|c|}
\hline Spectrum & $\mathrm{C}$ & $\mathrm{Al}$ & $\mathrm{Ti}$ & $\mathrm{Cr}$ & Co & $\mathrm{Ni}$ & $\mathrm{Hf}$ & $\mathrm{Ta}$ & W \\
\hline 1 & 2.52 & 3.83 & - & 20.36 & 43.55 & 18.09 & 0.73 & 0.46 & 10.46 \\
\hline 2 & 6.36 & 13.84 & 0.39 & 9.89 & 33.76 & 29.96 & - & 2.07 & 3.73 \\
\hline 3 & 11.54 & 0.60 & 2.51 & 4.89 & 10.10 & 4.30 & 22.56 & 40.90 & 2.59 \\
\hline 4 & 8.98 & 0.64 & 2.72 & 4.03 & 8.39 & 3.24 & 26.80 & 42.92 & 2.27 \\
\hline 5 & 9.65 & 0.46 & 2.86 & 3.92 & 8.69 & 3.34 & 22.57 & 46.67 & 1.85 \\
\hline 6 & 5.05 & 14.13 & 0.48 & 9.86 & 34.77 & 29.69 & - & 1.56 & 4.45 \\
\hline
\end{tabular}

(Ta, Hf, W)C carbides in deposited metal are the main strengthener at the temperature of up to $1200{ }^{\circ} \mathrm{C}$ and higher. TaC monocarbide prevailing in the weld is strongly bound to the matrix compared to other carbide phases.

Alloying of PWA 795 alloy by hafnium in the amount of 1 wt.\% causes a relative reduction of volume fraction of carbide precipitates of pin morphology. The first to form particles of (Hf, $\mathrm{Ti}) \mathrm{C}$ carbides are additional solidification centers and promote precipitation of carbides in a more favourable form as discrete faceted particles, that was observed by us after testing (see Figure 8, $d$; Table 4). Hafnium alloying improves weld metal oxidation resistance [9].

Aluminium present in the deposit material (4.4 wt.\%) has an important role in ensuring high-temperature resistance of deposited welds. First, in weld metal it guarantees formation of $\mathrm{Al}_{2} \mathrm{O}_{3}$ film during oxidation, preserving its protective properties at temperature above $1000{ }^{\circ} \mathrm{C}$. Secondly, when studying the initial structure of deposited weld metal, regular precipitates of $\beta$ (Ni, Co)Al intermetallic phase of $0.5-0.7 \mu \mathrm{m}$ size ensuring material oxidation resistance, are observed alongside strengthening carbide phases in matrix solution. Intermetallic phase present in PWA 795 alloy has a high stability in the cobalt matrix compared to nickel-base alloys at temperature above $1000{ }^{\circ} \mathrm{C}$. This is attributable to slow diffusion of aluminium and yttrium to the surface during soaking at high temperature. During testing this phase coagulates, being preserved in the greater part of the deposited weld and being a reserve of aluminium in weld composition (see Figure 8, $d$ and Table 4) [13].

It is known that yttrium in the amount of 0.34-0.40 wt.\% (alongside rare-earth elements - cerium, lanthanum, gadolinium) has an effective protective effect at high temperature oxidation [14].

Earlier considered reduction of the weight of samples deposited by alloys without yttrium is due to the fact that during cooling at each test cycle the scale cracks and delaminates. Poor ad- hesion of the film to the substrate is related to presence of pores, which form as a result of condensation of vacancies at scale-substrate boundary, forming as a result of element diffusion from metal into oxide film. Yttrium addition into nickel (cobalt) alloys leads to a considerable reduction of oxide film microporosity [15]. Lowering of defect rate in $\mathrm{Cr}_{2} \mathrm{O}_{3}$ film due to yttrium penetration into it was established [16]. This element reduces the diffusion flow of oxygen ions due to a large atomic radius, precipitating predominantly on vacancies, dislocations, subgrains and grain boundaries. This results in retardation of diffusion processes and oxidation resistance of protective film grows accordingly.

Owing to a higher chemical activity of yttrium to oxygen than that of base metal, including chromium and aluminium, yttrium binds the coming oxygen, releasing a relatively large amount of reserve chromium in the surface layers, and thus ensuring scale resistance of deposit metal.

Alloying by yttrium leads to formation of a zone containing highly-dispersed $\mathrm{Y}_{2} \mathrm{O}_{3}$ oxide particles in the subsurface layer of scale. Yttrium presence suppresses on the alloy or in the weld formation of $\mathrm{NiO}$ and $\mathrm{NiWO}_{4}$ oxides, not having any protective properties, owing to stabilization of $\mathrm{Cr}_{2} \mathrm{O}_{3}, \mathrm{Al}_{2} \mathrm{O}_{3}$ and $\mathrm{Ni}(\mathrm{Cr}, \mathrm{Al}) \mathrm{O}_{4}$ spinel. Penetration of yttrium into them and dissolution of $\mathrm{Y}_{2} \mathrm{O}_{3}$ oxide results in formation of $(\mathrm{Cr}, \mathrm{Y})_{2} \mathrm{O}_{3}$ and $\mathrm{Ni}(\mathrm{Cr}, \mathrm{Al}, \mathrm{Y}) \mathrm{O}_{4}$ oxides. A confirmation of yttrium penetration into the oxides are their unusually large lattice parameter values: for $(\mathrm{Cr}$, $\mathrm{Y}_{2} \mathrm{O}_{3} a=5.42-5.43 \mathrm{~nm}$, and for $\mathrm{Ni}(\mathrm{Cr}, \mathrm{Al}) \mathrm{O}_{4}$ $a=8.35 \mathrm{~nm}$.

Protective capacity of the oxides is also due to smaller number of faults in their crystalline lattice, greater force of ion binding, smaller coefficient of self-diffusion in it, as well as formation of a surface protective oxide film with a denser structure than that of $\mathrm{NiO}$ and $\mathrm{NiWO}_{4}$ oxides.

Yttrium is used to improve oxidation resistance of alloys of various types and coatings, on which protective $\mathrm{Al}_{2} \mathrm{O}_{3}$ film forms during oxida- 
tion. It is capable of improving the alloy oxidation resistance. If the alloy contains enough chromium, then at oxidation and formation of $\mathrm{Cr}_{2} \mathrm{O}_{3}$ oxide, yttrium improves its oxidation resistance not only at static, but also at cyclic oxidation (particularly for cobalt alloys) [9, 11].

At cyclic oxidation of the alloy with yttrium (as in our case) the protective film mainly preserves its integrity and has a good adhesion to the substrate being protected. At a high affinity to oxygen yttrium actively diffuses to the interphase (with an oxidizing medium) and forms oxides [17]. These Y-containing particles are localized near the protective $\mathrm{Al}_{2} \mathrm{O}_{3}$ film, i.e. in the zone with a high activity of oxygen and aluminium (chromium) and are readily enriched in chromium, thus leading to formation of $\mathrm{YAlO}_{3}$ and $\mathrm{YAl}_{5} \mathrm{O}_{12}$ yttrium granates. These are exactly the compounds that grow into protective $\mathrm{Al}_{2} \mathrm{O}_{3}$ film and ensure a reliable adhesion of the film to the substrate [13].

Thus, the high oxidation resistance of the deposited material - PWA 795 alloy - is determined by optimum alloying of cobalt base and its modifying by active components (yttrium and hafnium) [18]. In this composition yttrium ensures a high adhesion of oxide film to deposit material. At sufficient reserve of yttrium and low rate of yttrium diffusion to the surface in the cobalt alloy a high stability of $\mathrm{Ni}(\mathrm{Co}) \mathrm{Y}$ intermetallic compared to $\mathrm{Ni}-\mathrm{Co}-\mathrm{Cr}-\mathrm{Al}$ alloys is also ensured that determines the deposited metal oxidation resistance. Yttrium stabilizes the oxide films of aluminium oxide and chromium oxide on the alloy surface, that ensures increased oxidation resistance and allows in some cases elimination of protective coatings on turbine blades.

Hafnium has a positive influence on strength and ductility properties of deposited alloy. Modifying role of hafnium was manifested in that during oxidation disperse $\mathrm{HfO}_{2}$ particles «decorated» the inner boundaries of $\alpha-\mathrm{Al}_{2} \mathrm{O}_{3}$ film (see
Figure 8, $b$ and Table 3 ). This boundary strengthening has a positive effect on creep resistance of oxide film [18].

The question of complex repair includes not only re-tailoring airfoil upper tip by hardfacing, but also subsequent operations of product mechanical (abrasive) treatment, formation of airfoil upper tip (whisker), finish two-step heat treatment of the product, including application of a protective coating. An urgent task under these conditions is that of protection of working surface of single-crystal blades operating at 1100$1200{ }^{\circ} \mathrm{C}$ and made from Re-containing single-crystal alloys with limit content of alloying elements. Alloying of high-temperature nickel alloys by refractory metals and reduction of the number of elements providing satisfactory oxidation resistance of GTU hot section products, as well as carbon elimination from the composition, requires application of protective coatings safeguarding against high-temperature oxidation.

At selection of coating compositions it is necessary to take into account base alloy composition and coating oxidation resistance, which is determined not only by integral content of aluminium, chromium, cobalt, etc., time of its performance loss by the following mechanism: $\gamma+\beta(\mathrm{NiAl}) \rightarrow$ $\rightarrow \gamma+\beta+\gamma^{\prime}\left(\mathrm{Ni}_{3} \mathrm{Al}\right) \rightarrow \gamma+\gamma^{\prime}$, but also by the restoration ability of the film of spinel $\alpha-\mathrm{Al}_{2} \mathrm{O}_{3}+$ $+\alpha-\mathrm{Cr}_{2} \mathrm{O}_{3}$ or $\mathrm{Ni}(\mathrm{Cr}, \mathrm{Al})_{2} \mathrm{O}_{4}$, and a set of physical, chemical and mechanical properties.

In parallel with deposition on single-crystal alloy CMSX-4, work was performed on deposition of PWA 795 material on equiaxially solidified alloy ZMI-3U with subsequent deposition of oxidation-resistant coating of $\mathrm{Co}-\mathrm{Ni}-\mathrm{Cr}-\mathrm{Al}-$ $\mathrm{Y}$ system. Investigation results demonstrated a good matching of substrate material and repair deposit with protective coating layer. Interphases were dense, defect-free, without pronounced developed diffusion zones (Figure 10).

In order to confirm the above established advantages of application of PWA 795 deposition

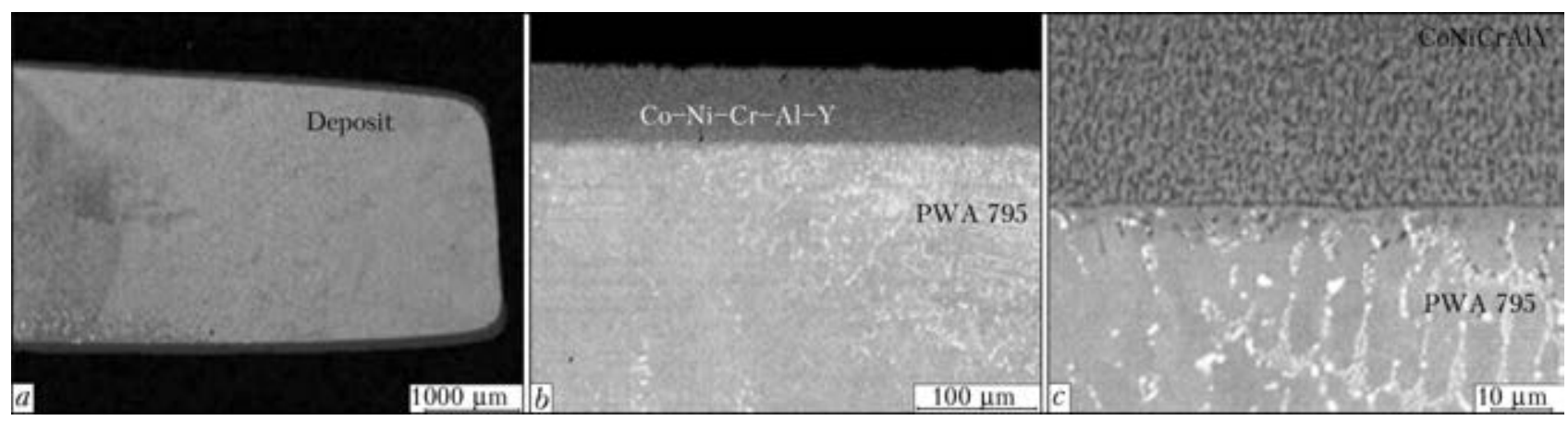

Figure 10. Microstructure of the tip of GKT-10-4 blade re-tailored by TIG hardfacing process with deposited protective coating 
on single-crystal CMSX-4 alloy, it is rational to perform comprehensive repair of the blade with subsequent electron beam deposition of thermal barrier NiCoCrAlY $/ \mathrm{ZrO}_{2}-\mathrm{Y}_{2} \mathrm{O}_{3}$ coating.

\section{Conclusions}

1. For comparative assessment of oxidation resistance of filler materials deposited on single-crystal alloy CMSX-4, thermal cycling tests were performed (at $t_{\max }=1150{ }^{\circ} \mathrm{C}$, cycle time $-1 \mathrm{~h}$ ) on samples with deposited welds and on base alloy sample.

2. IN 625 alloy is a good material for repair of items by deposition of oxidation-resistant alloys at working temperature of parts of up to $950{ }^{\circ} \mathrm{C}$. At higher temperatures and strict thermal cycling loading modes the produced welds burn out completely. Therefore, application of oxidation-resistant coatings on blades with such repair does not ensure satisfactory protection from oxidation at high service temperatures of high-heat GTU.

3. In terms of oxidation kinetics, PWA 795 filler material turned out to be the most oxidation-resistant, ensuring minimum oxidation rate of deposited weld. Thickness of frontal oxide film on weld surface did not exceed $10 \mu \mathrm{m}$ at local oxidation depth of not more than $30 \mu \mathrm{m}$. Oxide film forming on PWA 795 alloy has a doublelayer structure and ensures good protection of deposited metal from high-temperature oxidation. Good adhesion of the film to weld metal is noted, which is due to the alloying complex of the alloy and its yttrium content.

4. Tantalum and hafnium bind carbon (0.35 wt.\%) into $\mathrm{MeC}$ carbide phases and improve their morphology, perfecting carbide strengthening mechanism, accordingly. Tantalum present in the alloy in the amount of $2.7 \mathrm{wt} . \%$ influences thermal stability of deposit material, and hafnium improves weld metal ductility, owing to dispersion of carbide particles along grain boundaries and their spheroidization.

5. Presence of aluminium and nickel in cobalt filler material promotes formation of $\beta-(\mathrm{Ni}$, Co)Al-phase in the weld, ensuring material oxidation resistance. This phase is preserved in the greater part of the weld also after 400 test thermal cycles.

6. Cobalt-based filler materials ensure satisfactory oxidation resistance at high $\left(1150{ }^{\circ} \mathrm{C}\right)$ test temperature. Welds formed with application of cobalt filler materials, are not prone to development of cracks caused by dispersion hardening (similar to nickel ones) even in the presence of stray grains, forming during solidification. Selection of cobalt-based filler is also justified in that the main strengthening phase in it - carbides - are more stable than $\gamma^{\prime}$-phase (in nickel alloys) and they dissolve to a smaller degree at $1150{ }^{\circ} \mathrm{C}$.

1. Shukin, S., Annerfeldt, M., Bjorkman, M. (2008) Siemens SGT-800 industrial gas turbine enhanced to 47 MW. In: Proc. of ASME Turbo Expo 2008 on Power for Land, Sea and Air (June 9-13, 2008, Germany), 1-6.

2. Wilson, B.C., Hickman, J.A., Fuchs, G.E. (2003) The effect of solution heat treatment on a single-crystal Ni-based superalloy. JOM, 3, 35-40.

3. Wortman, D.J., Duderstadt, E.C., Nelson, W.A. (1990) Bond coat development for thermal barrier coating. Transact. of ASME. J. Eng. Gas Turbines Power, 12(10), 527-530.

4. Belyavin, A.F., Fedotov, D.A., Kurenkova, V.V. et al. (2013) Restoration of single-crystal blades using argon-arc surfacing and deposition of thermal-barrier coating. Pt 1. Sovr. Elektrometallurgiya, 1, 49-57.

5. Anderson, T.D., DuPont, J.N. (2010) Stray grain formation and solidification cracking susceptibility of single crystal Ni-base superalloy CMSX-4. Met. and Materials Transact. A, 41(1), 181-195.

6. Shalin, R.E., Svetlov, I.L., Kachanov, E.B. et al. (1997) Single crystals of nickel heat-resistant alloys. Moscow: Mashinostroenie.

7. Sieborgen, D., Brehm, H., Wunderlich, F. et al. (2001) Temperature dependence of lattice parameter, misfit and thermal expansion coefficient of matrix, $\gamma^{\prime}$ phase and superalloy. Z. Metallkd, 92, 58-61.

8. Caron, P., Lavigne, O. (2011) Recent studies at ONERA on superalloys for single crystal turbine blades. $J$. Aerospace Lab., Issue 3, 11, 1-14.

9. Kablov, E.N. (2001) Cast blades of gas turbine engines. Moscow: MISiS.

10. Tikhomirova, E.A., Azizov, T.N., Sidokhin, E.F. (2012) On thermal fatigue of heat-resistant alloys. Aviats. Materialy i Tekhnologii, 3, 3-5.

11. Kolomytsev, P.T. (1979) Heat-resistant diffusion coatings. Moscow: Metallurgiya.

12. Jackson, R.D. (2009) The effect of bond coat oxidation on the microstructure and endurance of two thermal barrier coating systems: Dis.

13. Toscano, J. (2008) Influence of composition and processing on the oxidation behavior of MCrAlYcoatings for TBC applications. Energy \& Environment, 28, 187.

14. Nikitin, V.N. (1987) Corrosion and protection of gas turbine blades. Leningrad: Mashinostroenie.

15. Tien, I.K., Rand, W.H. (1972) The effect of active element addition in void formation during oxidation. Ser Metal, 1, 55-57.

16. Michels, H.T. (1976) The effect of dispersed reactive metal oxides on the oxidation resistance of nickel$20 \%$ chromium alloys. Met. Transact., 3, 379-388.

17. Malashenko, V.S., Shelkovoj, A.N., Grabin, V.V. et al. (2000) Life of condensation thermal barrier coatings in current heat-resistant nickel alloy. Problemy Spetselektrometallurgii, 1, 23-24.

18. Liu, J. (2007) Mechanism of lifetime improvement in thermal barrier coatings with $H f$ or $Y$ modification of CMSX-4 superalloy substrates: Dis.

Received 25.10.2013 